\title{
Artistic Practices in Interventions for Disadvantaged Groups: Aid with Music
}

\author{
Ç. Sevin, A. Ege, and E. Erbay
}

\begin{abstract}
Artistic activities have long been used by professionals as a powerful tool in developing the individuals' social functioning and increasing their life quality. In this study, the music's use and its positive impacts in the studies carried out with the disadvantaged groups within the scope of social work practices will be dwelled on. Positive effects of music on disadvantaged groups are important in terms of turning music into an aid practice as well as music being an art.
\end{abstract}

Index Terms-Disadvantaged groups, aid with music, art, social work.

\section{INTRODUCTION}

Art tells us about life, events we encounter during our lives, all creatures in short, existence. But today, art has started to gain a further perspective. Beyond being just a tool that keeps people entertained, art's therapeutical properties are both being expressed and proved by researches and practices in the scientific world. Many art fields' therapeutic properties are discussed within the literature, yet this study focuses on music.

Music has a distinctive importance in social work interventions. The universality of music is an indisputable fact. When we look around, we see each person dealing with music whether professional, or amateur, or just as a listener. Because according to Robarts, music is intrinsic to our emotional and social everyday living, and not dependent on acquired musical skills [1]. Similarly Star, set forth that music is a part of our being and even our bodies are made up of rhythmic systems. With its beauty, music nourishes us and our souls; "it calms even the cruelest hearts, music speaks when words fail." [2].

This magic within the music's nature was blended with various techniques and methods over time and turned into a structure that heals, enhances and supports people. The foundations of this topic were first laid in the United States and the United Kingdom. But today these practices are feasible in all over the world, mainly Europe. The literature on the healing, enhancing and supporting effects of music gets richer and richer every day.

In Europe and America, the sciences of psychology and psychiatry define this aspect of music as "music therapy." Within the scope of the field and limit of application of social work, as an applied profession and an academic field, the writers of this study find it more suitable to use the word "aid" instead of "therapy." The reason of this is that the

Manuscript received November 25, 2014; revised January 21, 2015.

The authors are with the Department of Social Work, the Hacettepe University, Turkey (e-mail: csevin@hacettepe.edu.tr, ahmetege@hacettepe.edu.tr, eerbay@hacettepe.edu.tr). notion and the practice of music therapy are not fully adopted in Turkey. The implemented practice is more related to the concept of aid and the function of the social work is more related with social rehabilitation than psychological treatment.

In this study the definition, scope, used methods and application fields of aid with music, world widely known yet an uncommon practice field in Turkey, will be defined through a social work perspective.

\section{CONCEPTUAL APPROACH TO AID WITH Music}

Music is a non-invasive medium that increases self-expression, self-esteem, motor skills, coordination and socialization. It enhances the individual's creativity, inventiveness, independence and success. Activities carried out with music may result in positive responses [3].

Aid with music is defined as "the use of sounds and music within an evolving relationship between client and therapist to support and encourage physical, mental, social, spiritual and emotional well-being." [4].

According to another definition, "aid with music is a systematic process of intervention wherein the therapist (social worker, psychiatrist, or psychologist) helps the client to promote health, using music experiences and the relationships that develop through them as dynamic forces of change." [5]. the definitions in the literature, generally emphasizes music's treating goal. Instead of considering this process only as a treatment aid with music's other values, such as acquiring new skills, increasing self-respect and self-confidence and keeping away the stress and worries are also underlined.

Aid with music is a way to bring about positive changes in psychological, physical, cognitive or social functioning of people with health or learning problems, used by an authorized person. The staff who carry out aid with music usually work in psychiatric hospitals, rehabilitative facilities, medical hospitals, outpatient clinics, day-care treatment centers, agencies serving developmentally disabled persons, community mental health centers, drug and alcohol programs, senior citizens' centers, nursing homes, hospice programs, correctional facilities, halfway houses, schools and private practices [6].

The use of music within therapeutic purposes emerged in the 1950s in Europe and America, especially in hospitals, when its calming nature was used with a multidisciplinary approach. Within that period, Alvin carried out studies on how the melody and the rhythm of the music can be used in therapeutic approach. As pioneers in this field in the 1970s, Nordoff and Robbins studied on how music can be practiced on children with disabilities with some improvisation or 
advanced preparation [7]. It was observed that when the concept first developed, its fields of practice were mostly hospitals and people with disabilities. But within the period, and with the development of different approaches and methods, aid with music's field of practice has expanded.

The point where aid with music is now depends on the idea that everyone is born with a relation with music and this musicality situates itself in our brains and preservers its presence even after severe neurological trauma or problems [1].

The situation is that after over 50 years and with changes and developments, today aid with music is considered as a profession. Especially in the United States and the United Kingdom, this topic is an undergraduate major in various universities. And with several certificate programs, the number of the practitioners in this field is showing an increase.

\section{FIELDS OF PRACTICE OF AID WITH MUSIC IN SOCIAL WORK}

Carrying out a professional practice in a juvenile prison in Ankara was the driving force for the authors of this study to use the concept of "aid with music" in social work and to produce more information on this topic.

Within the scope of a voluntary works carried out by a non-governmental organization operating in Ankara and dealing with children's prosperity, various practices were carried out aiming to the adaptation of the children in juvenile prison. In this project, the authors' support was asked owing to their musical skills (playing the guitar and baglama). Children were given percussion instruments and asked to make music using the instruments. One of the children, taking the instrument said: "what a great thing to smash a head with." But later on he got caught up with the music, started to better communicate with his friends and regularly participated to the activities. Here, the authors realized the transforming effect of the music. A child being dragged to crime, perceived the musical instrument as an offensive weapon. But later on, the music's effect on the child's perception was very clear.

Art and as in the example above music, have a function that brings out the individual's inner power, helps them to discover their creativity and enriches their perception towards life. This function fully corresponds to the philosophy of social work. According to the International Federation of Social Worker, social work is a profession as well as an applied academic discipline. Social work inspires change, development and social cohesion and helps people to feel stronger and more self-confident. The essential parts of the social work are human rights, social justice, collective responsibility and respect for diversities [8]. While trying to realize these changes and developments, social work focuses on the individual's emancipation and their discovery of self-power. In this vein, integrating music into social work institutions that carry on social work practices would further strengthen the future interventions.

The rapid expansion of aid with music in research and practice levels in Europe and the United States, provided diversity in social work practice areas. Studies were firstly carried out in hospitals and educational institutions for people with disabilities, but later on broadened for disadvantaged groups including neglected, abused and substance dependent individuals. The use of music with respect to different practice fields and problems were discussed by the authors below:

Field of People With Disabilities: This field expresses one of the initial points of aid with music. This field has one of the most comprehensive information pools in practice and research levels. According to Meadowes, there are six main goals of practices carried out with people with disabilities [9]:

1) Fulfilling the individual's basic needs (creating a trustworthy and responsive environment),

2) Developing the individual's sense of self,

3) Establishing or re-establishing interpersonal relationships,

4) Developing specific skills,

5) Dispelling pathological behavior, and

6) Developing an awareness and sensitivity to the beauty of music.

Alongside with a successful intervention process, music was effective in resolving the lingual problems of individuals with disabilities and resulted in positive effects in their motor skills development. Again with cognitive and mental activities resulting from applied techniques, individuals have shown educational level improvements and some positive developments were observed in resolving psychological and social problems owing to the relaxing elements of music [5].

It is obvious that goals towards people with disabilities are quite obvious. When the literature is studied, it can be seen that the positive effects of "“group work", one of the intervention methods in social work, are widely stressed. The most ideal method in aid with music is to carry out the group work in parallel with individual work. This method will increase the benefits of the aid.

Field of Medicine and Mental Health: In many ways, hospitals can create an environment that affects individuals adversely. In addition to physical, psychological and social problems arising from diseases, adaptation problems, limited movement and inability to carry out activities can be sources of stress and concern for individuals. In this vein, aid with help is used in hospitals for overcoming stress, reducing concern and creating leisure activities. When studying the practice examples, it is observed that music is particularly used for terminally-ill patients. Music is also used for patients who will undergo an operation, making them relax before their operations.

It is also known that music is used in the field of mental health. Especially for individuals in crisis, aid with music is known to be effective. There are three stages of aid with music practices within the field of mental health. In the interest stage, the client is considerably unfamiliar with the process and constantly supported by the professional for self-expression. At this stage the client gets interested in the process. The second stage is learning and the individual starts to get involved in the techniques implemented. The last stage of improvisation is the most appropriate time for an effective practice. Because in this stage, the individual starts to express himself/herself and participates in the process. 
Individual takes responsibility and guides the professional into his/her inner world [6].

Problem of Neglect and Abuse: Neglect and abuse may cause severe and permanent problems in the individual's developmental process. In the cases of neglect and abuse, aid with music sets off from the alienation of the individual. The objective is the individual to form relations with the society, express himself/herself and share his/her experiences throughout the aid process [1]. In neglected and abused individuals, loneliness, depression and insecurity are often encountered situations. In practices where music is used as an instrument, individuals find the opportunity to re-communicate with society. Sharing music turns into a social rehabilitation and individuals may gain their abilities back to express their thoughts and feelings to other people and to trust.

Problem of Substance Abuse: Aid with music and substance use have a thing in common: they both alter emotions and mood. Most of the clients stated that both music and drugs have increased their energy and drove them apart from reality. The objective of the aid with music process is to bring forward the thin line between the two. Owing to the aid with music individuals start to use their energy in a healthy way and manage to change their decision-making mechanisms [10].

Newly developed aid with music practices mostly focus on four fields mentioned above. But looking at all the researches carried out, it would not be wrong to say that much major developments are expected in fields of practice. Some studies regarding women in shelter homes, prisons and schools are also being carried out. Aid with help is practiced on disadvantaged individuals, so it can also be used on many problematic fields.

\section{TeChNiQues USED IN AID WITH MusiC}

Aid with music can be practiced using multiple techniques. In accordance with the purpose of the practice, appropriate techniques are chosen in appropriate times. Along with differences and diversities among techniques, new models and approaches emerged in aid with music, in time.

The techniques used in aid with music are; song writing, song selection, singing, poetry analysis and discussion, improvisation and instrument playing. The goal is to express the subconscious emotions that are not recited [11].

Song Writing: Song writing can be re-writing the lyrics of an existing song or creating a whole brand new song with a new melody and lyrics. Writing songs are often more easier for clients in terms of expressing themselves rather than oral expression.

Song Selection: In this practice, clients choose a song and this song is sung either together or by the professional. In fact, this technique reflects the indirect expression of the emotions. Clients may find orally expressing themselves more difficult. Therefore they find it easier to tell themselves through music. This process is less worrying, enhances their self-confidence, enriches their self-identity, supports decision-making and develops social interaction.

Singing: Besides helping with pronunciation, fluency and breath controlling, singing also increases physical comfort.
Singing helps individuals to gain self-awareness and feeling of belonging. Singing facilitates expressing and remembering. It is important to pay attention to what the selected songs mean to the clients.

Lyrics Analysis and Discussion: Listening and discussing a song's lyrics may help the client to express many problems. Each individual interprets music and lyrics differently and lyrics may open doors for a discussion. If a client seeks helps or support to express his/her feelings, the professional may come up with a song for discussion. This technique does not considered as a risk for clients to open up. The cognitive functions of this technique enable the client to re-gain self-identity and facilitate the loss process.

Improvisation: Clients may express their feelings and thoughts through improvisation. The professional supports the client to play an instrument and asks him/her to express himself/herself how he/she feels. And they may make music together. The improvisation technique enables the client and the professional to interact without a word limit and creates an easier way to reach deeper feelings. The most important aspect of the technique is that the client participates into the practice directly.

Playing an Instrument: Professional motivates the client to participate to the practice and helps with the development of the motor coordination. In this technique, the use of percussion instruments by clients who do not prefer to express themselves orally enables the emotional discharge and expression. The objectives of this technique are to ensure participation, creating an alternative method for self-expression and to support decision-making.

As is seen, there are many different techniques in aid with music. It is important to put forward the fields of practice of aid with music, after mentioning the methods and techniques.

\section{CONCLUSION}

Recently, different approaches to interventions aimed at problems of the disadvantaged groups are increasing. Without a doubt, one of these approaches is artistic practices/aid with music. Aid with art has many branches but aid with music has made great progress in terms of information source.

Aid with music was first used in hospitals and private educational institutions. But today it is used in many different fields and became an independent discipline. In the United States and Europe, undergraduate programs on aid with music are becoming rapidly widespread.

The universality of the music makes social work practices more successful. Aid with music helps individuals to open up their inner worlds, gain new skills, discover their creativities, develop their communication skills and reduce their stress and concerns.

Social work provides services to a wide range of groups. Social work practices might be needed by all individuals who have lost social functionality. In the process of re-gaining social functionality, combining micro, mezzo and macro level practices of social work with the liberating magic of music may result in even more positive results. In this respect, it is highly important to develop models to implement such practices in social work institutions. 


\section{REFERENCES}

[1] J. Robarts, "Music therapy with sexually abused children," Clinical Child Psychology and Psychiatry, vol. 11, pp. 249-269, 2006.

[2] R. J. Star, "Music therapy in hospice care," American Journal of Hospice \& Palliative Care, no. 6, pp. 739-742, 1999.

[3] S. Sausser and R. J. Waller, "A model for music therapy with students with emotional and behavioral disorders," The Arts in Psychotherapy, vol. 33, pp. 1-10, 2006.

[4] J. O'Kelly and J. Koffman "Multidisciplinary perspectives of music therapy in adult palliative care," Palliative Medicine, vol. 21, pp. 235-241, 2007.

[5] J. Pellitteri, "Music therapy in the special education setting," Journal of Educational and Psychological Consultation, pp. 379-391, 2000.

[6] J. Tervo, "Music therapy for adolescents," Clinical Child Psychology and Psychiatry, vol. 6, pp. 79-91, 2001.

[7] M. Lefevre, "Playing with sound: The therapeutic use of music in direct work with children," Child and Family Social Work, vol. 9, pp. 333-345, 2004.

[8] IFSW. (International Federation of Social Workers). [Online]. Available: http://ifsw.org/policies/definition-of-social-work/

[9] J. Stephenson, "Music therapy and the education of students with severe disabilities," Education and Training in Developmental Disabilities, pp. 290-299, vol. 43, 2006.

[10] F. A. Baker, L. M. Gleadhill, and A. D. Genevieve, "Music therapy and emotional exploration: Exposing substance theme pack abuse clients to the experiences of non-drug-induced emotions," The Arts in Psychotherapy, pp. 321-330, 2007.

[11] A. C. Cortes, "The use of music in facilitating emotional expression in the terminally Ill," American Journal of Hospice and Palliative Medicine, vol. 21, pp. 255-260, 2004.

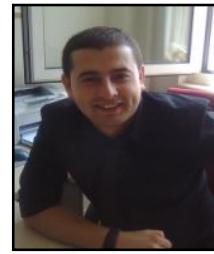

institutions

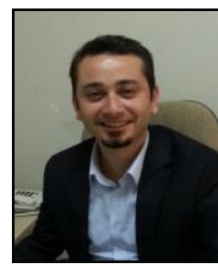

Ahmet Ege was born in Ankara in 1987. He graduated from Hacettepe University, Department of Social work in 2010 . He is continuing his postgraduate education in the same department. His major field is social work.

He used to work in NGO's in child and youth projects as a social worker. Since 2012 he has been a research assistant in Hacettepe University, Department of Social Work. His research interests are child welfare, youth welfare, social work education and social work skills.

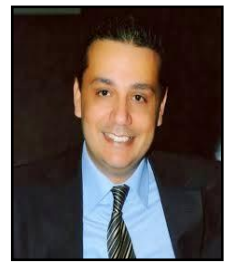

Ercüment Erbay was born in Ankara in 1980. After graduated from primary, secondary and high school in Ankara, he entered Hacettepe University School of Social Work in 1999 and graduated from this school with honors in 2004.

$\mathrm{He}$ worked as a research assistant between 2006-2011 at the Hacettepe University, Department of Social Work and got his PhD degree in 2011. He is working as an associate professor at Hacettepe University now. He is also a vice-principal at the Children Right's Practice and Research Center. 